\title{
Local anesthetic systemic toxicity: current perspectives
}

This article was published in the following Dove Press journal:

Local and Regional Anesthesia

\author{
Kariem El-Boghdadly ${ }^{1,2}$ \\ Amit Pawa' \\ $\mathrm{Ki}$ Jinn $\mathrm{Chin}^{3}$ \\ 'Department of Anaesthesia, Guy's \\ and St Thomas' NHS Foundation Trust, \\ London, UK; ${ }^{2}$ School of Medicine, \\ King's College London, London, UK; \\ ${ }^{3}$ Department of Anesthesia, Toronto \\ Western Hospital, University of \\ Toronto, Ontario, Canada
}

\begin{abstract}
Local anesthetic systemic toxicity (LAST) is a life-threatening adverse event that may occur after the administration of local anesthetic drugs through a variety of routes. Increasing use of local anesthetic techniques in various healthcare settings makes contemporary understanding of LAST highly relevant. Recent data have demonstrated that the underlying mechanisms of LAST are multifactorial, with diverse cellular effects in the central nervous system and cardiovascular system. Although neurological presentation is most common, LAST often presents atypically, and one-fifth of the reported cases present with isolated cardiovascular disturbance. There are several risk factors that are associated with the drug used and the administration technique. LAST can be mitigated by targeting the modifiable risk factors, including the use of ultrasound for regional anesthetic techniques and restricting drug dosage. There have been significant developments in our understanding of LAST treatment. Key advances include early administration of lipid emulsion therapy, prompt seizure management, and careful selection of cardiovascular supportive pharmacotherapy. Cognizance of the mechanisms, risk factors, prevention, and therapy of LAST is vital to any practitioner using local anesthetic drugs in their clinical practice.
\end{abstract}

Keywords: local anesthetic, toxicity, therapy, regional anesthesia

\section{Introduction}

Local anesthetic systemic toxicity (LAST) is a life-threatening adverse event associated with the increasingly prevalent utilization of local anesthetic (LA) techniques throughout various health care settings, with an incidence currently estimated to be $0.03 \%$, or 0.27 episodes per 1,000 peripheral nerve blocks. The evolution of LA techniques, such as the emergence of high-volume fascial plane approaches, ${ }^{1,2}$ the growing relevance of continuous catheter techniques, ${ }^{3}$ employing multiple LA techniques in the same patient, ${ }^{4}$ and the use of tumescent anesthesia ${ }^{5}$ all contribute to the ongoing risks of LAST. The underlying pathophysiology of LAST and its treatment have been the subject of significant investigation in recent years, and our understanding of these has evolved substantially. This article presents a contemporary perspective on the current state of understanding of LAST, including the mechanisms, presentation, and treatment.

\section{Mechanisms}

The mechanisms by which LAST produces its clinical manifestations can be elucidated from the well-described pharmacokinetics of LAs. ${ }^{6}$ 


\section{Pharmacokinetics of LAs}

Peak plasma concentration of LA and the time taken to attain peak levels are governed by the rate of systemic absorption. This, in turn, is determined by the vascular supply of injection sites, as well as the mass of drug deposition. ${ }^{6,7}$ Once in the plasma, LA distribution to organs is determined by perfusion, with well-perfused tissues such as the brain, heart, liver, and lungs receiving the bulk of LA mass initially. ${ }^{8}$ Within the plasma, it is the free portion of the drug that determines the clinical and toxic effects and that undergoes metabolism. Although aminoamide LAs such as lidocaine, bupivacaine, and ropivacaine are highly protein bound to $\alpha_{1}$-acid glycoprotein, the protein binding of aminoester LAs, including procaine and chloroprocaine, is so small as to be clinically unimportant (Figure 1). Aminoamide LAs undergo significant first-pass enzymatic metabolism by hepatic cytochrome P450 (CYP/ CYP450) enzymes, with variable rates depending on drug pharmacology. Aminoester agents undergo rapid hydrolysis by plasma cholinesterases, producing water-soluble metabolites excreted in urine. ${ }^{9}$

\section{Mechanisms of action of LAs}

LA agents exert their effect by attaching to the intracellular domain of the $\mathrm{Na}_{\mathrm{v}}$ channel, thereby inhibiting neuronal ion transfer and depolarization, and preventing neuronal transmission. ${ }^{10}$ LAs may also bind to and block $\mathrm{K}^{+}$channels, $\mathrm{Ca}^{2+}$ channels, the $\mathrm{Na}^{+}-\mathrm{K}^{+}$ATPase channel, as well as several other targets. ${ }^{11-15}$ Notably, LAs can interfere with intracellular and transmembrane cell signaling, ${ }^{16-19}$ affecting the metabolic processes of cyclic adenosine monophosphate, protein kinase $\mathrm{B}$ (Akt), and 5-adeonosine monophosphate activated protein kinase (AMPK), among other stimulatory kinases. ${ }^{20-22}$ LAs have also been shown to impair mitochondrial metabolism, adenosine triphosphate production, inhibit the ryanodine receptor at the sarcoplasmic reticulum, and reduce $\mathrm{Ca}^{2+}$ sensitivity of myofilaments. The plethora of LA targets (Figure 2) explains the complex mechanistic and clinical picture of LAST.

\section{Central nervous system (CNS) toxicity}

Increasing plasma concentrations of LA initially compromises cortical inhibitory pathways by blockade of $\mathrm{Na}_{\mathrm{V}}$ channels, disrupting inhibitory neuron depolarization. ${ }^{23}$ Inhibiting these pathways leads to excitatory clinical features of sensory and visual changes, muscular activation, and subsequent seizure activity. As the plasma concentrations of LA rise, excitatory pathways are affected, producing a depressive phase of neurological toxicity, with loss of consciousness, coma, and respiratory arrest.

\section{Cardiovascular system (CVS) toxicity}

The multitude of aforementioned LA molecular targets produces complex toxic features in the CVS, including conduction disturbances, myocardial dysfunction, and lability

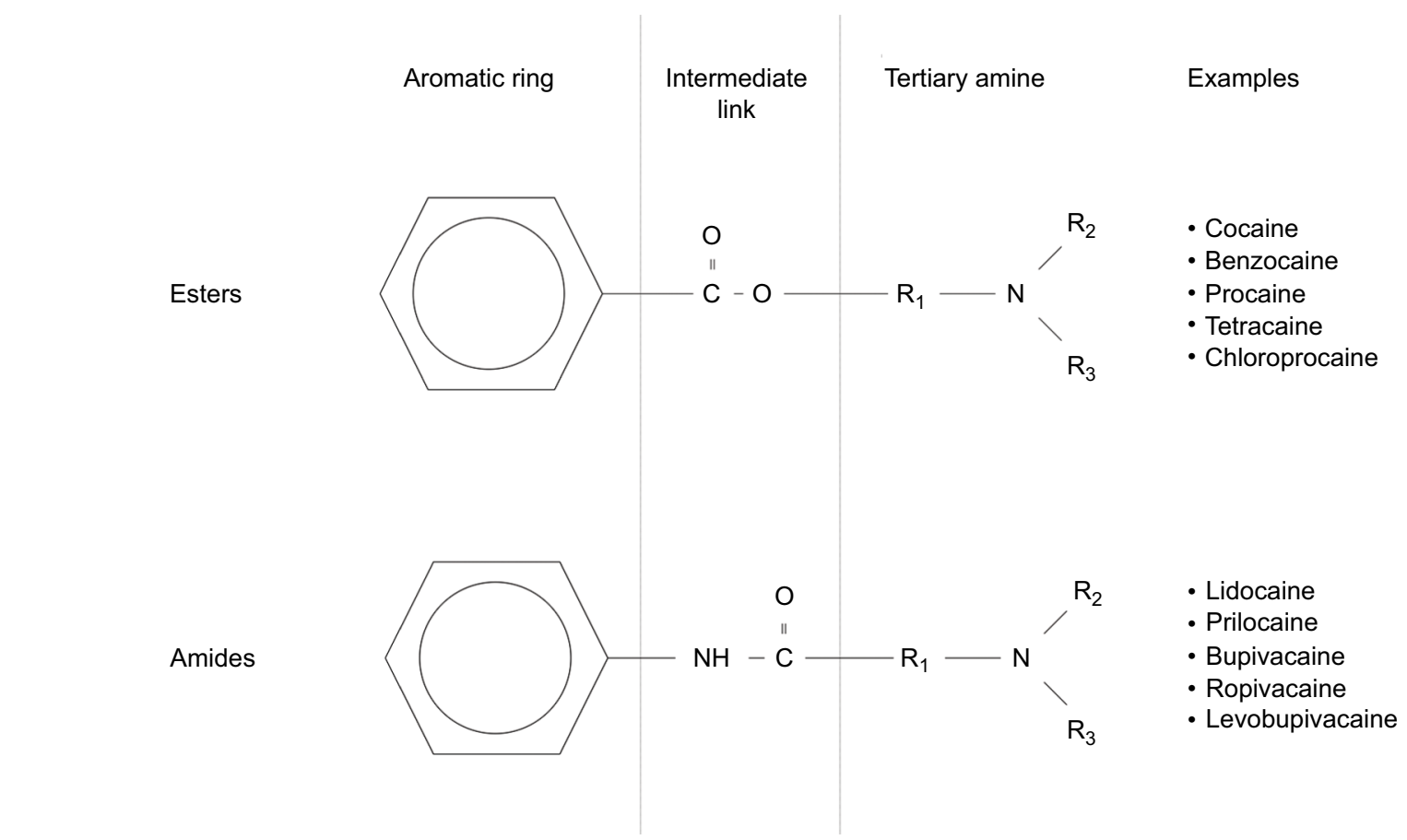

Figure I Chemical structures of ester and amide local anesthetic agents with examples of each. 


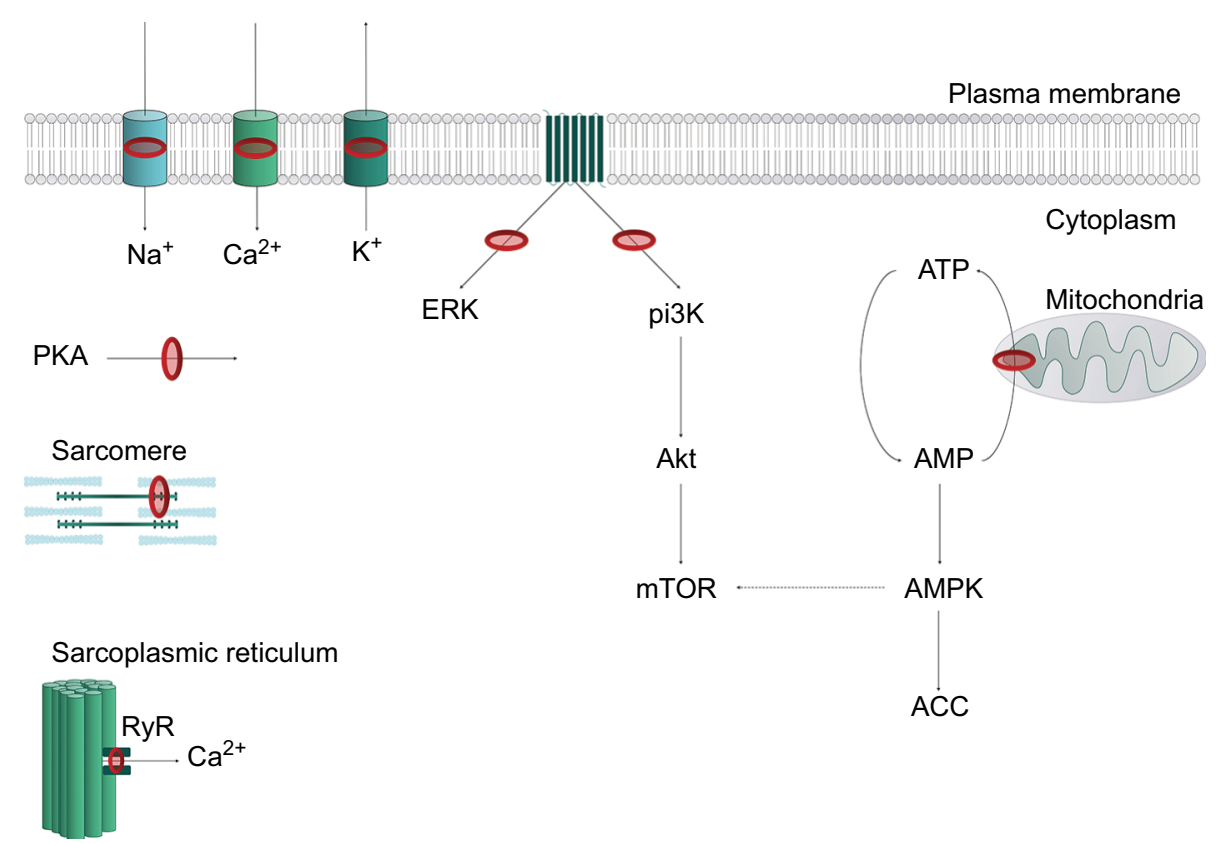

Figure 2 Representation of key LA cellular targets contributing to local anesthetic systemic toxicity.

Notes: In the plasma membrane, LAs block the $\mathrm{Na}$ channel $\left(\mathrm{Na}^{+}\right)$, potassium $\left(\mathrm{K}^{+}\right)$and calcium channels $\left(\mathrm{Ca}^{2+}\right)$. Inhibition of second messenger systems on metabotropic transmembrane G-protein-coupled receptors leads to inhibition of ERK and pi3K. This leads to dysregulation of downstream kinase pathways, including a reduction in Akt and, thus, mTOR. Mitochondrial phosphorylation of AMP to ATP is inhibited, leading to an increase in the inhibitory, energy-sensing kinase AMPK, which in turn further mitigates mTOR. Other inhibitory targets include PKA, calcium-dependent contractility inhibition at the sarcomere, and modulation of the RyR. Red rings represent sites of action of LAs. Dotted lines represent inhibitory actions.

Abbreviations: AMP, adenosine monophosphate; ATP, adenosine triphosphate; LA, local anesthetic; RyR, ryanodine receptor.

of peripheral vascular tone. The primary effects are likely to arise from rhythm disturbance, with other CVS effects being secondary. Normal conduction is disrupted by direct sodium channel blockade, chiefly at the bundle of His. By driving the resting membrane potential to a more negative level, action potential propagation is impaired, leading to prolonged $\mathrm{PR}$, QRS, and ST intervals. Re-entrant tachyarrhythmias and bradyarrhythmias ensue, which may be worsened by further potassium channel blockade, prolonging the QT interval.

Myocardial dysfunction has several contributory mechanisms. Calcium channel and $\mathrm{Na}^{+}-\mathrm{Ca}^{2+}$ exchange pump blockade reduces intracellular calcium stores and, thus, diminishes contractility. The net result of interruption of Akt, AMPK, thereby interrupting insulin-driven intracellular glucose metabolism, along with the reduction of intracellular adenosine triphosphate reserves, and impaired cyclic adenosine monophosphate production further contributes to reduced myocardial contractility (Figure 2). A direct $\mathrm{pH}$ related suppressive effect of LAs is exerted on the neuronal control mechanisms of baroreceptors, ${ }^{24}$ as well as a negative effect on systemic vascular tone.

\section{Presentation}

Although $40 \%$ of LAST presents atypically, ${ }^{25} \mathrm{CNS}$ toxicity is the most common feature of LAST $(68 \%-77 \%),{ }^{26,27}$ primarily in the form of seizures. Diverse early manifestations have been described (although many are likely underreported), and may include peri-oral paresthesia, confusion, audiovisual disturbances, dysgeusia, agitation, or reduced level of consciousness. One-third of the reported cases of LAST begin with CNS features that progress to involve CVS signs, and one-fifth of LAST episodes present with isolated CVS disturbances. ${ }^{27}$ Again, protean features of CVS toxicity are apparent, but dysrhythmias, conduction deficits, hypotension, and eventually cardiac arrest - most commonly of an asystolic nature - may be seen. ${ }^{28}$ LAST events most frequently occur immediately following injection of $\mathrm{LA}^{29}$ and recent data demonstrate that delayed presentation may occur at various time points up to several days following commencement of an infusion.

\section{Risk factors}

The risk factors for developing LAST can be categorized into those that are related to the injected drug, the patient, or the technique.

\section{Drug}

The cardiovascular collapse/CNS (CC/CNS) ratio is "the ratio of drug dose required to cause catastrophic cardiovascular collapse to the drug dose required to produce seizures."26 
A low $\mathrm{CC} / \mathrm{CNS}$ ratio is associated with more cardiotoxic agents, ${ }^{30}$ while LAs with a higher $\mathrm{CC} / \mathrm{CNS}$ ratio have a greater safety margin. This is because the earlier presentation of CNS features may expedite earlier diagnosis (and thus, treatment) of LAST before cardiovascular collapse ensues. Ropivacaine and levobupivacaine, for example, have higher $\mathrm{CC} / \mathrm{CNS}$ ratios than racemic bupivacaine; therefore, it seems logical to preferentially use these drugs when long-acting LAs are desired. Vigilance is always required, however, as all LA drugs may cause LAST. ${ }^{28,31,32}$

LAs also have differing intrinsic vasoactive effects. Levobupivacaine and ropivacaine have dose-dependent vasoactive properties that may potentially prolong duration and slow systemic absorption, as opposed to bupivacaine which has vasodilatory properties and may lead to more rapid systemic absorption.

The appropriate dose of LA should be the lowest dose that achieves the desired duration and extent of analgesia or anesthesia. ${ }^{25}$ A given dose of LA will be associated with inter-individual variation in plasma concentrations depending on the site and speed of administration or patient demographics. Such observations have questioned per kilogram and maximum recommended doses in adults, ${ }^{33}$ particularly as the maximum weight-based dose varies between countries and texts. However, these serve as a useful reference and maximum doses should be adhered to, especially in patients with low body weight (Table 1).

\section{Patient}

\section{Age}

Patients at the extremes of age have consistently been shown to be at the greatest risk of LAST. ${ }^{27}$ Neonates and infants have

Table I Suggested dosing recommendations for commonly used local anesthetic agents

\begin{tabular}{llllll}
\hline $\begin{array}{lllll}\text { Local } \\
\text { anesthetic }\end{array}$ & $\begin{array}{l}\text { Plain } \\
\text { Maximum } \\
\text { dose }\end{array}$ & $\begin{array}{l}\text { Maximum } \\
\text { dose }\end{array}$ & & $\begin{array}{l}\text { Maximum } \\
\text { dose }\end{array}$ & $\begin{array}{l}\text { Maximum } \\
\text { dose }\end{array}$ \\
\hline Bupivacaine & $2 \mathrm{mg} \cdot \mathrm{kg}^{-1}$ & $175 \mathrm{mg}$ & & $3 \mathrm{mg} \cdot \mathrm{kg}^{-1}$ & $225 \mathrm{mg}$ \\
Levobupivacaine & $2 \mathrm{mg} \cdot \mathrm{kg}^{-1}$ & $200 \mathrm{mg}$ & & $3 \mathrm{mg} \cdot \mathrm{kg}^{-1}$ & $225 \mathrm{mg}$ \\
Lidocaine & $5 \mathrm{mg} \cdot \mathrm{kg}^{-1}$ & $350 \mathrm{mg}$ & & $7 \mathrm{mg} \cdot \mathrm{kg}^{-1}$ & $500 \mathrm{mg}$ \\
Mepivacaine & $5 \mathrm{mg} \cdot \mathrm{kg}^{-1}$ & $350 \mathrm{mg}$ & & $7 \mathrm{mg} \cdot \mathrm{kg}^{-1}$ & $500 \mathrm{mg}$ \\
Ropivacaine & $3 \mathrm{mg} \cdot \mathrm{kg}^{-1}$ & $200 \mathrm{mg}$ & & $3 \mathrm{mg} \cdot \mathrm{kg}^{-1}$ & $250 \mathrm{mg}$ \\
Prilocaine & $6 \mathrm{mg} \cdot \mathrm{kg}^{-1}$ & $400 \mathrm{mg}$ & & $8 \mathrm{mg} \cdot \mathrm{kg}^{-1}$ & $600 \mathrm{mg}$ \\
\hline
\end{tabular}

Notes: Data from Berde and Strichartz. ${ }^{92}$ Dadure C, Sola C, Dalens B, Capdevila $X$. Regional anesthesia in children. In: Miller RD (Ed.). Miller's Anesthesia, eighth ed. Philadelphia: Elsevier; 2015:2718.93 American Academy of Pediatrics; American Academy of Pediatric Dentistry, Cote CJ, Wilson S; Work Group on Sedation. Guidelines for monitoring and management of pediatric patients during and after sedation for diagnostic and therapeutic procedures: an update. Pediatrics 2006; I 18:2587-2602. ${ }^{94}$ reduced plasma concentrations of the binding protein $\alpha_{1}$-acid glycoprotein and immature hepatic enzyme systems that may increase the free fraction of LA in the plasma. Dosing should, therefore, be reduced by $15 \%$ in patients $<4$ months of age.

Elderly patients have reduced clearance of LA due to reduced metabolic organ perfusion and pharmacodynamic function, thereby increasing the potential of drug accumulation with repeated boluses of LA or continuous infusions. Elderly patients may have multiple comorbidities, and degenerative changes might render the elderly more susceptible to the systemic effects of LA, despite relatively unchanged levels of protein binding. As the skeletal muscle may act as a reservoir for LA, reduced skeletal muscle mass has also been implicated in increasing the risk of $\mathrm{LAST}^{27}$ It seems reasonable, therefore, to suggest a dose reduction of $10 \%-20 \%$ in these patients. ${ }^{26}$

\section{Pregnancy}

Parturients have reduced plasma concentrations of $\alpha_{1}$-acid glycoprotein and an increased cardiac output. Together, these lead to accelerated perfusion of injection sites, rapid LA absorption, and higher peak free LA concentrations. Additionally, epidural venous engorgement may increase the drug absorption and/or the possibility of catheter migration. For the combination of aforementioned reasons, parturients are at an increased risk of LAST, and therefore, it is recommended that doses of peripheral and central neuraxial LAs be reduced. ${ }^{33}$

\section{Renal disease}

Patients with severe renal disease not only have a hyperdynamic circulation and reduced clearance of LAs, but also have an increased $\alpha_{1}$-acid glycoprotein concentration. As a result, free plasma concentrations are largely unchanged and dose reduction is often unnecessary, unless the patient is uremic with metabolic acidosis..$^{34,35}$

\section{Cardiac disease}

Patients with cardiac disease are at an increased risk of LAST. Those with pre-existing conduction disorders may be predisposed to cardiovascular toxicity, and careful dosing as well as the use of less cardiotoxic drugs such as ropivacaine or levobupivacaine is recommended.

Patients with severe cardiac dysfunction are particularly susceptible to LA-induced myocardial depression and arrhythmias due to reduced hepatic and renal perfusion leading to reduced metabolism and elimination, respectively. Poor perfusion to the injection site may reduce the peak plasma 
concentration of LA, but if the circulation time is prolonged, the detection of an intravenous injection of LA (by detection of a tracer substance such as epinephrine) may be delayed. Dose reduction is unnecessary in mild-moderate heart failure where tissue perfusion is preserved, but is recommended in severe heart failure. ${ }^{33}$

\section{Hepatic dysfunction}

Isolated hepatic dysfunction per se does not necessitate dose adjustment for single-shot regional anesthetic techniques despite a reduced hepatic clearance of LAs. A larger volume of distribution and maintenance of $\alpha_{1}$-acid glycoprotein synthesis provide a safety margin in patients with hepatic disease. However, in patients receiving repeated boluses or continuous infusions of LA, or those with coexisting cardiac or renal disease, dose reduction is recommended. ${ }^{26}$

\section{Technique}

Data from large registries and published case reports indicate that the risk of LAST differs between block types. Vasques et $\mathrm{al}^{36}$ and Gitman and Barrington ${ }^{27}$ have summarized the published case report data between 2010 and 2014 and between 2014 and 2016, respectively, identifying a total of 125 cases. As a group, LA infiltration techniques were most commonly implicated, accounting for $20 \%$ of events. This was followed by central neuraxial blocks (epidural and caudal) in 15\% and continuous infusion of LA in 13\% of events. Possible factors that may have influenced these results include the dose of LA typically administered and the vascularity of the site involved. A notable proportion of events $(18 \%)$ occurred following penile blocks in children, and is likely the result of a confluence of factors that include a more susceptible patient population, injection into a highly vascular area, and the use of doses close to the maximum recommended limits. ${ }^{37}$

In an analysis of $>25,000$ peripheral nerve blocks from the Australian and New Zealand Registry of Regional Anesthesia database, ${ }^{38}$ the calculated risk of LAST with lower limb blocks (no events reported) was significantly lower than that of upper limb blocks, which was in turn lower than that for paravertebral blocks. This again may reflect the relative vascularity of the sites of injection and the corresponding plasma concentration of LA that results from a given dose. ${ }^{39}$

\section{Fascial plane blocks}

Fascial plane blocks have become increasingly popular in recent years as a method of providing regional anesthesia of the torso. Most studies pertain to the transversus abdominis plane (TAP) block, but they all share the common characteristic of large-volume $(>20 \mathrm{~mL})$ LA injection into a fascial intermuscular plane. As muscles generally have a rich vascular supply, there is a significant risk of LAST from systemic absorption of LA. The time to peak plasma concentration following a TAP block is 30 minutes on average, but can be as long as 90 minutes in some individuals. ${ }^{40-43}$ This may also vary with the type and site of block; for example, the rectus sheath block has been shown to have a consistently longer time to peak concentration (60 minutes) compared to the TAP block. ${ }^{41,42}$ Although most studies report that the average maximum LA plasma concentration following TAP block with commonly used dosing regimens falls below the generally accepted toxic threshold, there are consistently individuals in whom this is approached or exceeded. ${ }^{40,43-45}$ Epinephrine reduces the systemic absorption and the maximum LA plasma concentrations - even for ropivacaine and thus should always be added to the LA solution where possible. ${ }^{43,45}$ Lower concentrations and doses of LA should also be used, particularly if epinephrine is omitted. ${ }^{46}$ The American Society of Regional Anesthesia and Pain Medicine guidelines further recommend that dosing should be based on lean body weight. ${ }^{47}$

\section{Continuous catheter techniques}

The risk of LAST appears to be higher with continuous peripheral nerve blockade compared to single-shot techniques, ${ }^{48}$ and this is likely related to the accumulating dose of LA. One study of bilateral TAP block catheters found that a $10 \mathrm{~mL} \cdot \mathrm{h}^{-1}$ infusion of $0.2 \%$ ropivacaine, initiated 30 minutes after a loading dose of $100 \mathrm{mg}$ ropivacaine per side, resulted in a continuing rise in plasma concentration up to 48 hours. ${ }^{49}$ There was wide interindividual variability, with a large number of subjects having total concentrations exceeding the toxic threshold. However, it was reassuring to note that the unbound ropivacaine concentration was much lower and remained well below toxic threshold. This was linked to the post-surgical rise in acute phase reactive $\alpha_{1}$-acid glycoprotein and suggests a reasonable margin of safety when infusions are used in the clinical context.

\section{Local infiltration analgesia (LIA) in total joint arthroplasty}

LIA is an increasingly popular technique that involves highvolume periarticular LA infiltration by surgeons, usually in the context of joint replacement surgery. Available studies in total hip and knee arthroplasty indicate that the average peak LA plasma concentrations remain below toxic thresholds. ${ }^{50-53}$ 
However, as usual, significant interindividual variation means that this threshold can be crossed, and LAST has been reported ${ }^{54}$ Absorption is higher in total hip arthroplasty than total knee arthroplasty, ${ }^{53}$ and LA dosage should be reduced accordingly. There is presently no available pharmacokinetic data related to LIA for shoulder arthroplasty, but it is worth noting that the baseline incidence of LAST is higher compared to lower limb arthroplasty. ${ }^{55}$ Prolonged vigilance remains essential, given that the time to peak plasma concentrations can vary from 2 to 6 hours, and that the patient population is often elderly with multiple comorbidities that render them more susceptible to LAST.

\section{Liposomal bupivacaine}

Published data in the peer-reviewed literature on the risk of LAST with liposomal bupivacaine remain scarce. It is reassuring to note that the maximum plasma concentrations of bupivacaine at the maximum US Food and Drug Administration-recommended dose (266 mg or $3.8 \mathrm{mg} \cdot \mathrm{kg}^{-1}$ ) remains well below toxic thresholds, ${ }^{56,57}$ and that intravascular injection appears safer compared to non-liposomal bupivacaine preparations. ${ }^{58}$ Nevertheless, it must be noted that these studies do not take into account the common clinical practice of combining liposomal bupivacaine with plain bupivacaine and other LAs to hasten analgesic onset. It is well recognized that interaction between the LAs can cause premature release of bupivacaine from the liposomes, ${ }^{59,60}$ and the manufacturer recommends against injecting any other LA $<20$ minutes after administration of liposomal bupivacaine. An article drawing on the US Food and Drug Administration's Adverse Event Reporting Data cautioned that there was a likely association with LAST based on 130 cases reported between 2012 and 2016; they also cited two case reports that were not in the peerreviewed literature. The presentation of toxicity mirrors that reported from bupivacaine hydrochloride-induced LAST. ${ }^{61}$

\section{Tumescent local anesthesia}

Tumescent anesthesia for plastic surgical procedures such as liposuction involves the injection of extremely large volumes of lidocaine into subcutaneous tissues, usually with the addition of epinephrine for added safety. The American Society for Dermatologic Surgery Liposuction Guidelines recommend the maximal safe $\mathrm{mg} \cdot \mathrm{kg}^{-1}$ dosage of lidocaine as $55 \mathrm{mg} \cdot \mathrm{kg}^{-1} \cdot{ }^{62}$ However, a more recent pharmacokinetic study recommends lower limits of $45 \mathrm{mg} \cdot \mathrm{kg}^{-1}$, and $28 \mathrm{mg} \cdot \mathrm{kg}^{-1}$ if liposuction is not performed. ${ }^{63}$ It should be noted that this recommendation does not eliminate the risk entirely, but was designed to lower it to acceptable levels $(1: 2,000)$. Mortality has been exclusively reported in patients receiving general anesthesia, but clinical features may be insidious and may present late. ${ }^{64}$ Practitioners must, therefore, remain prepared to recognize and treat LAST. ${ }^{64}$

\section{Topical anesthesia of the oropharynx and airway}

LAST has been reported following topical anesthesia of the oropharynx and airway for a variety of procedures, including transesophageal echocardiography ${ }^{65}$ and bronchoscopy. ${ }^{66,67}$ The likely contributing factors ${ }^{68}$ include a perception that lidocaine is relatively safe, failure to monitor the doses being given, and increased susceptibility in patients with significant comorbidities. Systemic absorption of lidocaine depends, to an extent, on the mode of delivery. A significant proportion is lost to the atmosphere with nebulization and atomization, or swallowed and cleared through first-pass metabolism. As a result, the available evidence indicates that up to $9 \mathrm{mg} \cdot \mathrm{kg}^{-1}$ can be used safely in healthy patients. ${ }^{69,70}$

\section{Intravenous local anesthesia}

Intravenous injection of lidocaine has been used for acute and chronic pain states, with doses ranging between 1 and $3 \mathrm{mg} \cdot \mathrm{kg}^{-1}$ as a bolus and $1-5 \mathrm{mg} \cdot \mathrm{kg}^{-1} \cdot \mathrm{hour}^{-1}$ as an infusion to achieve therapeutic plasma levels of $2.5-3.5 \mu \mathrm{g} \cdot \mathrm{mL}^{-1}{ }^{68,71}$ Threshold serum plasma concentrations for mild toxicity and onset of neurological symptoms is reported to be $6 \mu \mathrm{g} \cdot \mathrm{mL}^{-1}$, with progression to cardiovascular compromise with plasma concentrations $>10 \mu \mathrm{g} \cdot \mathrm{mL}^{-1},{ }^{72}$ which is a reflection of a high $\mathrm{CC} / \mathrm{CNS}$ ratio. Mild CNS signs are reported in up to $11 \%$ of patients, while cardiovascular signs arise in $4 \%-15 \%$ of patients, ranging from bradycardia to atrial fibrillation. Susceptible patients may exhibit LAST with lower dosing regimens, ${ }^{73,74}$ and careful patient selection is important in considering intravenous lidocaine administration.

Intravenous regional anesthesia (Bier block) is associated with a significant risk of major complications, with symptoms and signs across the entire spectrum of LAST. Seizures have been reported with doses as low as $1.4 \mathrm{mg} \cdot \mathrm{kg}^{-1}$ of lidocaine, $4 \mathrm{mg} \cdot \mathrm{kg}^{-1}$ of prilocaine, and $1.3 \mathrm{mg} \cdot \mathrm{kg}^{-1}$ of bupivacaine, and cardiac arrest at doses as low as $2.5 \mathrm{mg} \cdot \mathrm{kg}^{-1}$ of lidocaine and $1.6 \mathrm{mg} \cdot \mathrm{kg}^{-1}$ of bupivacaine. ${ }^{75}$ Notably, LAST can occur even with an inflated tourniquet and up to 30 minutes following tourniquet deflation.

\section{Others}

Accumulated data from case reports, databases, and case series have highlighted several other risk factors for the development of LAST. Notably, a fifth of cases of LAST occur outside of the traditional hospital settings, and half of LAST occurs in the hands of non-anesthesiology specialists. 


\section{Prevention}

Prevention should be the priority for reducing the frequency and severity of LAST. ${ }^{47}$ No single intervention eliminates the risk, and therefore, prevention is a multifactorial process.

\section{Ultrasound-guided nerve blockade}

Ultrasound has been shown to reduce the risk of LAST by $60 \%-65 \%$ as compared to peripheral nervous stimulation alone. ${ }^{38,53,76}$ There are several explanations for this risk reduction. Increased accuracy of delivery permits reduction in volume and, therefore, dose of LA; the incidence of vascular puncture may be reduced; and visual cues signaling intravascular injection allow termination of injection before a significant dose is delivered. However, LAST events continue to occur despite the use of ultrasound, ${ }^{38}$ and ultrasound guidance does not impact the risk of LAST resulting from systemic absorption of LA.

\section{Drug and injection}

Restricting the drug dosage may contribute to LAST riskreduction. It is advisable to perform fractionated injection of LA in aliquots of $<5 \mathrm{~mL}$, pausing for $30-45$ seconds between injections,${ }^{26}$ with gentle aspiration before injection. This latter measure is still useful despite a false-negative rate of around $2 \%{ }^{47}$ Markers such as epinephrine may also mitigate the risk of intravascular injection, where addition of $15 \mu \mathrm{g} \cdot \mathrm{mL}^{-1}$ will increase the heart rate by $\geq 10$ beats per minute or systolic blood pressure by $\geq 15 \mathrm{mmHg}$. Practical interventions such as clear labeling of LA-containing syringes and meticulous handling of these syringes may be of benefit. The transition from Luer connectors to new ISO 80369 standard small-bore connecters might also reduce the risk of wrong route injection. ${ }^{77,78}$

\section{Treatment}

\section{Preparation}

All patients receiving injections of LA in doses sufficient to cause LAST should have oxygen, standard monitoring, and intravenous access applied. Monitoring should continue for at least 30 minutes after completion of injection, as delayed presentations are increasingly occurring. ${ }^{27,79}$ Immediate access to a LAST Management Checklist is advisable, and all medications and resuscitation equipment required should be immediately available, preferably in the form of a "LAST Rescue Kit". Despite data suggesting inconsistent adherence to standardized protocols, the value of these guidelines cannot be understated.

\section{Immediate management}

Immediate management involves the general safety and resuscitation measures that are essential in any emergency.
First, stop LA injection and call for help. The immediate priority is to manage the airway, breathing, and circulation.

\section{Maintain airway, oxygenation, and ventilation}

Prompt and effective airway management is crucial to prevent hypoxia, hypercapnia, and acidosis (metabolic or respiratory), which are known to potentiate LAST. The airway should be secured and $100 \%$ oxygen administered, bearing in mind that hyperventilation and respiratory alkalosis have also been demonstrated to be injurious. ${ }^{80}$

\section{Intravenous lipid emulsion therapy}

Recent advances in understanding of the mechanisms of action of lipid emulsion underscore the importance of this therapeutic modality in the management of LAST. Data suggest that lipid emulsion may shuttle any LA agent from high blood flow organs - such as the heart or brain - to storage or detoxification organs such as muscles or the liver. ${ }^{81}$ Lipid emulsion therapy may also improve the cardiac output and blood pressure (hence further facilitating the shuttling effect), while postconditioning myocardial protection may also occur. ${ }^{82-85}$ There is a paucity of large-scale, high-quality data demonstrating the clinical efficacy of lipid emulsion therapy, primarily due to the difficulties in valid data collection and the limited feasibility of prospective studies. ${ }^{86,87}$ However, animal studies demonstrate strong support for the use of lipid emulsion therapy in reducing mortality when applied in conjunction with resuscitative interventions. ${ }^{88}$

Early administration of $20 \%$ intravenous lipid emulsion therapy should, therefore, be an immediate priority after airway management in any LAST event that is judged to be potentially serious. Convergence of the different administration regimes between the American Society of Regional Anesthesia and Pain Medicine ${ }^{47}$ and the Association of Anesthetists of Great Britain and Ireland guidance ${ }^{89}$ has led to increased consistency in therapeutic protocols. An initial bolus of $100 \mathrm{~mL}$ should be administered over $2-3$ minutes ( $1.5 \mathrm{~mL} \cdot \mathrm{kg}^{-1}$ if the lean body weight is $<70 \mathrm{~kg}$ ). This is then to be followed by a $20 \%$ lipid emulsion infusion of 200-250 $\mathrm{mL}$ over $15-20$ minutes $\left(0.25 \mathrm{~mL} \cdot \mathrm{kg}^{-1} \cdot \mathrm{min}^{-1}\right.$ if the lean body weight is $<70 \mathrm{~kg}$ ). If circulatory stability is not attained, rebolusing up to two further times or increasing the infusion to $0.5 \mathrm{~mL} \cdot \mathrm{kg}^{-1} \cdot \mathrm{min}^{-1}$ is suggested. The maximum recommended dose of $20 \%$ lipid emulsion is $12 \mathrm{~mL} \cdot \mathrm{kg}^{-1}$.

\section{Seizure management}

Seizure activity may exacerbate metabolic acidosis, and prompt prevention and termination is crucial. Due to their cardiostable profile, benzodiazepines are the first-line therapy. 
Propofol should be avoided where there are signs of cardiovascular compromise, in view of the effect of large doses on depressing cardiac function, but small doses may be used. If seizures persist despite all efforts, low-dose neuromuscular blockade can be considered to reduce metabolic acidosis and hypoxia from ongoing muscular contraction.

\section{Cardiovascular support}

Advanced Cardiac Life Support algorithms for cardiopulmonary resuscitation must be followed should cardiac arrest occur. Chest compressions should be initiated immediately and continued until return of spontaneous circulation. If epinephrine is used, small initial doses of $\leq 1 \mu \mathrm{g} \cdot \mathrm{kg}^{-1}$ are preferred to avoid impaired pulmonary gas exchange and increased afterload. ${ }^{90}$ Vasopressin is not recommended for use as it has been associated with adverse outcomes in animal models. In the absence of rapid recovery following advanced life support measures and intravenous lipid emulsion therapy, early consideration should be given to cardiopulmonary bypass for circulatory support.

The inotropic effect of lipid emulsion therapy only occurs once the myocardial LA levels are below a threshold that corresponds to ion channel blocking concentrations. This emphasizes the importance of effective chest compressions to ensure coronary perfusion is sufficient to reduce LA tissue levels in order to obtain the benefit of lipid emulsion therapy.

If cardiac output is maintained but there are deleterious CVS effects - such as arrhythmias, conduction block, progressive hypotension, and bradycardia - standard Advanced Cardiac Life Support algorithms should be followed with the omission of LA, such as lidocaine, for the treatment of arrhythmia. Amiodarone is the first-line antiarrhythmic in the event of ventricular dysrhythmia.

\section{Post-event management}

Following an episode of LAST with CVS features, patients should be monitored for at least 6 hours, while isolated and rapidly terminating $\mathrm{CNS}$ features require patient monitoring for a minimum of 2 hours. It is advisable that cases should be reported to the registry at www.lipidrescue.org. ${ }^{91}$

\section{Conclusion}

LAST is a life-threatening adverse event, and recent advances in understanding the pathophysiological basis of the condition and its therapy will improve patient safety. It is imperative that practitioners who use LA in their clinical practice are cognizant of the mechanisms, risk factors, prevention, and therapeutic modalities.

\section{Author contributions}

All authors made substantial contributions to the conception and design of this manuscript, drafting the article, and final approval of the published version. All authors agree to be held accountable for all aspects of the work.

\section{Disclosure}

AP has received honoraria from GE Healthcare for teaching and consults for B Braun Medical Ltd. The authors report no conflicts of interest in this work.

\section{References}

1. El-Boghdadly K, Pawa A. The erector spinae plane block: plane and simple. Anaesthesia. 2017;72(4):434-438.

2. Forero M, Adhikary SD, Lopez H, Tsui C, Chin KJ. The Erector Spinae Plane Block. Reg Anesth Pain Med. 2016;41(5):621-627.

3. Ilfeld BM. Continuous peripheral nerve blocks: a review of the published evidence. Anesth Analg. 2011;113(4):904-925.

4. Pawa A, Wight J, Onwochei DN, et al. Combined thoracic paravertebral and pectoral nerve blocks for breast surgery under sedation: a prospective observational case series. Anaesthesia. 2018;73(4): 438-443.

5. Conroy PH, O’Rourke J. Tumescent anaesthesia. Surgeon. 2013;11(4): 210-221.

6. Dillane D, Finucane BT. Local anesthetic systemic toxicity. Can J Anesth Can D'anesthésie. 2010;57(4):368-380.

7. Butterworth JF. Models and mechanisms of local anesthetic cardiac toxicity: a review. Reg Anesth Pain Med. 2010;35(2):167-176.

8. Tucker GT. Pharmacokinetics of local anaesthetics. Br J Anaesth. 1986;58(7):717-731.

9. Becker DE, Reed KL. Local anesthetics: review of pharmacological considerations. Anesth Prog. 2012;59(2):90-102.

10. Butterworth JF, Strichartz GR. Molecular mechanisms of local anesthesia: a review. Anesthesiology. 1990;72(4):711-734.

11. Groban L, Dolinski SY. Differences in cardiac toxicity among ropivacaine, levobupivacaine, bupivacaine, and lidocaine. Techniques in Regional Anesthesia and Pain Management. 2001;5(2): $48-55$.

12. Komai H, Mcdowell TS. Local anesthetic inhibition of voltage-activated potassium currents in rat dorsal root ganglion neurons. Anesthesiology. 2001;94(6):1089-1095.

13. Valenzuela C, Delpón E, Tamkun MM, Tamargo J, Snyders DJ. Stereoselective block of a human cardiac potassium channel (Kv1.5) by bupivacaine enantiomers. Biophys J. 1995;69(2):418-427.

14. Coyle DE, Sperelakis N. Bupivacaine and lidocaine blockade of calciummediated slow action potentials in guinea pig ventricular muscle. J Pharmacol Exp Ther. 1987;242(3):1001-1005.

15. Clarkson CW, Hondeghem LM. Mechanism for Bupivacaine Depression of Cardiac Conduction. Anesthesiology. 1985;62(4):396-405.

16. Fettiplace MR, Kowal K, Ripper R, et al. Insulin Signaling in Bupivacaine-induced Cardiac Toxicity: Sensitization during Recovery and Potentiation by Lipid Emulsion. Anesthesiology. 2016;124(2): 428-442.

17. Piegeler T, Votta-Velis EG, Bakhshi FR, et al. Endothelial barrier protection by local anesthetics: ropivacaine and lidocaine block tumor necrosis factor- $\alpha$-induced endothelial cell Src activation. Anesthesiology. 2014;120(6):1414-1428.

18. Piegeler T, Votta-Velis EG, Liu G, et al. Antimetastatic potential of amide-linked local anesthetics: inhibition of lung adenocarcinoma cell migration and inflammatory Src signaling independent of sodium channel blockade. Anesthesiology. 2012;117(3):548-559. 
19. Butterworth JF 4th, Brownlow RC, Leith JP, Prielipp RC, Cole LR. Bupivacaine inhibits cyclic-3',5'-adenosine monophosphate production. A possible contributing factor to cardiovascular toxicity. Anesthesiology. 1993;79(1):88-95.

20. Pişkin Ö, Aydın BG, Pişkin ABG. Effects of insulin+glucose pretreatment on bupivacaine cardiotoxicity in rats. Hum Exp Toxicol. 2018;37(5):451-457.

21. Roth D, Pace NL, Lee A, et al. Airway physical examination tests for detection of difficult airway management in apparently normal adult patients. Cochrane Database Syst Rev. 2018;5(5):CD008874.

22. Schultze SM, Hemmings BA, Niessen M, Tschopp O. PI3K/AKT, MAPK and AMPK signalling: protein kinases in glucose homeostasis. Expert Rev Mol Med. 2012;14:e1.

23. Zink W, Graf BM. The toxicity of local anesthetics: the place of ropivacaine and levobupivacaine. Curr Opin Anaesthesiol. 2008;21(5):645-650.

24. Watanabe Y, Dohi S, Iida H, Ishiyama T. The effects of bupivacaine and ropivacaine on baroreflex sensitivity with or without respiratory acidosis and alkalosis in rats. Anesth Analg. 1997;84(2):398-404.

25. Neal JM, Bernards CM, Butterworth JF, et al. ASRA practice advisory on local anesthetic systemic toxicity. Reg Anesth Pain Med. 2010;35(2): $152-161$.

26. El-Boghdadly K, Chin KJ. Local anesthetic systemic toxicity: Continuing Professional Development. Can J Anaesth. 2016;63(3):330-349.

27. Gitman M, Barrington MJ. Local Anesthetic Systemic Toxicity: A Review of Recent Case Reports and Registries. Reg Anesth Pain Med. 2018;43(2):124-130.

28. di Gregorio G, Neal JM, Rosenquist RW, Weinberg GL. Clinical presentation of local anesthetic systemic toxicity: a review of published cases, 1979 to 2009. Reg Anesth Pain Med. 2010;35(2):181-187.

29. Mulroy MF. Systemic toxicity and cardiotoxicity from local anesthetics: incidence and preventive measures. Reg Anesth Pain Med. 2002;27(6):556-561.

30. Groban L. Central nervous system and cardiac effects from long-acting amide local anesthetic toxicity in the intact animal model. Reg Anesth Pain Med. 2003;28(1):3-11.

31. Breslin DS, Martin G, Macleod DB, D’Ercole F, Grant SA. Central nervous system toxicity following the administration of levobupivacaine for lumbar plexus block: A report of two cases. Reg Anesth Pain Med 2003;28(2):144-147.

32. Weiss E, Jolly C, Dumoulin JL, et al. Convulsions in 2 patients after bilateral ultrasound-guided transversus abdominis plane blocks for cesarean analgesia. Reg Anesth Pain Med. 2014;39(3):248-251.

33. Rosenberg PH, Veering BT, Urmey WF. Maximum recommended doses of local anesthetics: a multifactorial concept. Reg Anesth Pain Med. 2004;29(6):564-575.

34. Pere PJ, Ekstrand A, Salonen M, et al. Pharmacokinetics of ropivacaine in patients with chronic renal failure. Br J Anaesth. 2011;106(4): 512-521.

35. Pere P, Salonen M, Jokinen M, Rosenberg PH, Neuvonen PJ, Haasio J. Pharmacokinetics of ropivacaine in uremic and nonuremic patients after axillary brachial plexus block. Anesth Analg. 2003;96(2):563-569.

36. Vasques F, Behr AU, Weinberg G, Ori C, di Gregorio G. A Review of Local Anesthetic Systemic Toxicity Cases Since Publication of the American Society of Regional Anesthesia Recommendations. Reg Anesth Pain Med. 2015;40(6):1-705.

37. Yu RN, Houck CS, Casta A, Blum RH. Institutional Policy Changes to Prevent Cardiac Toxicity Associated With Bupivacaine Penile Blockade in Infants. Case Rep. 2016;7(3):71-75.

38. Barrington MJ, Kluger R. Ultrasound guidance reduces the risk of local anesthetic systemic toxicity following peripheral nerve blockade. Reg Anesth Pain Med. 2013;38(4):289-297.

39. Tucker GT, Moore DC, Bridenbaugh PO, Bridenbaugh LD, Thompson GE. Systemic absorption of mepivacaine in commonly used regional block procedures. Anesthesiology. 1972;37(3):277-287.
40. Trabelsi B, Charfi R, Bennasr L, et al. Pharmacokinetics of bupivacaine after bilateral ultrasound-guided transversus abdominis plane block following cesarean delivery under spinal anesthesia. Int J Obstet Anesth. 2017;32:17-20.

41. Murouchi T, Iwasaki S, Yamakage M. Chronological Changes in Ropivacaine Concentration and Analgesic Effects Between Transversus Abdominis Plane Block and Rectus Sheath Block. Reg Anesth Pain Med. 2015;40(5):568-571.

42. Yasumura R, Kobayashi Y, Ochiai R. A comparison of plasma levobupivacaine concentrations following transversus abdominis plane block and rectus sheath block. Anaesthesia. 2016;71(5):544-549.

43. Toju K, Shiraishi K, Hakozaki T, Isosu T, Murakawa M. Plasma ropivacaine concentration following ultrasound-guided subcostal transversus abdominis plane block in adults. J Anesth. 2015;29(1):146-148.

44. Bardsley H, Gristwood R, Baker H, Watson N, Nimmo W. A comparison of the cardiovascular effects of levobupivacaine and rac-bupivacaine following intravenous administration to healthy volunteers. $\mathrm{Br} \mathrm{J} \mathrm{Clin}$ Pharmacol. 1998;46(3):245-249.

45. Corvetto M a, Echevarría GC, De La Fuente N, Mosqueira L, Solari S, Altermatt FR. Comparison of plasma concentrations of levobupivacaine with and without epinephrine for transversus abdominis plane block. Reg Anesth Pain Med. 2012;37(6):633-637.

46. Miranda P, Corvetto MA, Altermatt FR, Araneda A, Echevarría GC, Cortínez LI. Levobupivacaine absorption pharmacokinetics with and without epinephrine during TAP block: analysis of doses based on the associated risk of local anaesthetic toxicity. Eur J Clin Pharmacol. 2016;72(10):1221-1227.

47. Neal JM, Barrington MJ, Fettiplace MR, et al. The Third American Society of Regional Anesthesia and Pain Medicine Practice Advisory on Local Anesthetic Systemic Toxicity: Executive Summary 2017. Reg Anesth Pain Med. 2018;43(2):113-123.

48. Gurnaney H, Kraemer FW, Maxwell L, Muhly WT, Schleelein L, Ganesh A. Ambulatory continuous peripheral nerve blocks in children and adolescents: a longitudinal 8-year single center study. Anesth Analg. 2014;118(3):621-627.

49. Kumar SK, Rao V, Morris RG, Watts RW, Westley IS, Ropivacaine WIS. Ropivacaine (total and unbound) and AGP concentrations after transversus abdominis plane block for analgesia after abdominal surgery. Ther Drug Monit. 2014;36(6):759-764.

50. Brydone AS, Souvatzoglou R, Abbas M, Watson DG, Mcdonald DA, Gill AM. Ropivacaine plasma levels following high-dose local infiltration analgesia for total knee arthroplasty. Anaesthesia. 2015;70(7):784-790.

51. Fenten MG, Bakker SM, Touw DJ, et al. Pharmacokinetics of $400 \mathrm{mg}$ ropivacaine after periarticular local infiltration analgesia for total knee arthroplasty. Acta Anaesthesiol Scand. 2017;61(3):338-345.

52. Affas F, Eksborg S, Wretenberg P, Olofsson C, Stiller CO. Ropivacaine pharmacokinetics after local infiltration analgesia in hip arthroplasty. Anesth Analg. 2014;119(4):996-999.

53. Affas F. Local infiltration analgesia in knee and hip arthroplasty efficacy and safety. Scand J Pain. 2016;13:59-66.

54. Fenten MG, Rohrbach A, Wymenga AB, Stienstra R. Systemic local anesthetic toxicity after local infiltration analgesia following a polyethylene tibial insert exchange: a case report. Reg Anesth Pain Med. 2014;39(3):264-265.

55. Rubin DS, Matsumoto MM, Weinberg G, Roth S. Local Anesthetic Systemic Toxicity in Total Joint Arthroplasty: Incidence and Risk Factors in the United States From the National Inpatient Sample 1998-2013. Reg Anesth Pain Med. 2018;43(2):131-137.

56. Hu D, Onel E, Singla N, Kramer WG, Hadzic A. Pharmacokinetic profile of liposome bupivacaine injection following a single administration at the surgical site. Clin Drug Investig. 2013;33(2):109-115.

57. Rice D, Heil JW, Biernat L. Pharmacokinetic Profile and Tolerability of Liposomal Bupivacaine Following a Repeated Dose via Local Subcutaneous Infiltration in Healthy Volunteers. Clin Drug Investig. 2017;37(3):249-257. 
58. Joshi GP, Patou G, Kharitonov V. The safety of liposome bupivacaine following various routes of administration in animals. J Pain Res. 2015;8:781-789.

59. Burbridge M, Jaffe RA. Exparel ${ }^{\circledR}$ : A New Local Anesthetic with Special Safety Concerns. Anesth Analg. 2015;121(4):1113-1114.

60. Kharitonov V. A review of the compatibility of liposome bupivacaine with other drug products and commonly used implant materials. Postgrad Med. 2014;126(1):129-138.

61. Aggarwal N. Local anesthetics systemic toxicity association with exparel (bupivacaine liposome)- a pharmacovigilance evaluation. Expert Opin Drug Saf. 2018;17(6):1-7.

62. Svedman KJ, Coldiron B, Coleman WP, et al. ASDS guidelines of care for tumescent liposuction. Dermatol Surg. 2006;32(5):709-716.

63. Klein JA, Jeske DR. Estimated Maximal Safe Dosages of Tumescent Lidocaine. Anesth Analg. 2016;122(5):1350-1359.

64. Weinberg G. Local Anesthetic Systemic Toxicity and Liposuction: Looking Back, Looking Forward. Anesth Analg. 2016;122(5):1250-1252.

65. Bacon B, Silverton N, Katz M, Heath E, Bull DA, Harig J, Tonna JE. Local Anesthetic Systemic Toxicity Induced Cardiac Arrest After Topicalization for Transesophageal Echocardiography and Subsequent Treatment With Extracorporeal Cardiopulmonary Resuscitation. J Cardiothorac Vasc Anesth. 2018 Jan 31. pii: S1053-0770(18)30048-X.

66. Gaïes E, Jebabli N, Lakhal M, Klouz A, Salouage I, Trabelsi S. Delayed convulsion after lidocaine instillation for bronchoscopy. Rev Mal Respir. 2016;33(5):388-390.

67. Wu FL, Razzaghi A, Souney PF. Seizure after lidocaine for bronchoscopy: case report and review of the use of lidocaine in airway anesthesia. Pharmacotherapy. 1993;13(1):72-78.

68. Weibel S, Jokinen J, Pace NL, et al. Efficacy and safety of intravenous lidocaine for postoperative analgesia and recovery after surgery: a systematic review with trial sequential analysis. Br J Anaesth. 2016;116(6): $770-783$.

69. Woodruff C, Wieczorek PM, Schricker T, Vinet B, Backman SB. Atomised lidocaine for airway topical anaesthesia in the morbidly obese: $1 \%$ compared with 2\%. Anaesthesia. 2010;65(1):12-17.

70. Efthimiou J, Higenbottam T, Holt D, Cochrane GM. Plasma concentrations of lignocaine during fibreoptic bronchoscopy. Thorax. 1982;37(1):68-71.

71. Kandil E, Melikman E, Adinoff B. Lidocaine Infusion: A Promising Therapeutic Approach for Chronic Pain. J Anesth Clin Res. 2017; $8(1)$.

72. Eipe N, Gupta S, Penning J. Intravenous lidocaine for acute pain: an evidence-based clinical update. BJA Educ. 2016;16(9):292-298.

73. Wong GK, Joo DT, Mcdonnell C. Lipid resuscitation in a carnitine deficient child following intravascular migration of an epidural catheter. Anaesthesia. 2010;65(2):192-195.

74. Haldar R, Dubey M, Rastogi A, Singh PK. Intravenous Lignocaine to Blunt Extubation Responses: A Double-Edged Sword. Am J Ther. 2016;23(2):e646-e648.

75. Guay J. Adverse events associated with intravenous regional anesthesia (Bier block): a systematic review of complications. J Clin Anesth. 2009;21(8):585-594.

76. Orebaugh SL, Kentor ML, Williams BA. Adverse outcomes associated with nerve stimulator-guided and ultrasound-guided peripheral nerve blocks by supervised trainees: update of a single-site database. Reg Anesth Pain Med. 2012;37(6):577-582.
77. Litman RS, Smith VI, Mainland P. New solutions to reduce wrong route medication errors. Paediatr Anaesth. 2018;28(1):8-12.

78. Risk Management Analysis Committee of the French Society for Anesthesia and Critical Care (SFAR), French Society for Clinical Pharmacy (SFPC), Piriou V, Theissen A, Arzalier-Daret S. Preventing medication errors in anesthesia and critical care (abbreviated version). Anaesth Crit Care Pain Med. 2017;36(4):253-258.

79. Vasques F, Behr AU, Weinberg G, Ori C, di Gregorio G. A Review of Local Anesthetic Systemic Toxicity Cases Since Publication of the American Society of Regional Anesthesia Recommendations: To Whom It May Concern. Reg Anesth Pain Med. 2015;40(6):698-705.

80. Mochizuki T, Sato S. Hypocapnia prolongs bradycardia induced by bupivacaine or levobupivacaine in isolated rat hearts. Can J Anaesth. 2008;55(12):836-846.

81. Fettiplace MR, Lis K, Ripper R, et al. Multi-modal contributions to detoxification of acute pharmacotoxicity by a triglyceride microemulsion. J Control Release. 2015;198:62-70.

82. Rahman S, Li J, Bopassa JC, et al. Phosphorylation of GSK-3 $\beta$ mediates intralipid-induced cardioprotection against ischemia/reperfusion injury. Anesthesiology. 2011;115(2):242-253.

83. Lou P-H, Lucchinetti E, Zhang L, et al. The Mechanism of Intralipid®Mediated Cardioprotection Complex IV Inhibition by the Active Metabolite, Palmitoylcarnitine, Generates Reactive Oxygen Species and Activates Reperfusion Injury Salvage Kinases. PLoS One. 2014;9(1):e87205.

84. Stehr SN, Ziegeler JC, Pexa A, et al. The effects of lipid infusion on myocardial function and bioenergetics in 1-bupivacaine toxicity in the isolated rat heart. Anesth Analg. 2007;104(1):186-192.

85. Fettiplace MR, Ripper R, Lis K, et al. Rapid cardiotonic effects of lipid emulsion infusion*. Crit Care Med. 2013;41(8):e156-e162.

86. Weinberg G. Current evidence supports use of lipid rescue therapy in local anaesthetic systemic toxicity. Acta Anaesthesiol Scand. 2017;61(4):365-368.

87. Harvey M, Cave G. Lipid emulsion in local anesthetic toxicity. Curr Opin Anaesthesiol. 2017;30(5):632-638.

88. Fettiplace MR, Mccabe DJ. Lipid emulsion improves survival in animal models of local anesthetic toxicity: a meta-analysis. Clin Toxicol. 2017; 55(7):617-623.

89. Association of Anaesthetists of Great Britain and Ireland. AAGBI Safety Guideline: Management of Severe Local Anaesthetic Toxicity. https:// www.aagbi.org/sites/default/files/la_toxicity_2010_0.pdf. Accessed July 08, 2018.

90. Wang QG, Wu C, Xia Y, et al. Epinephrine deteriorates pulmonary gas exchange in a rat model of bupivacaine-induced cardiotoxicity: a threshold dose of epinephrine. Reg Anesth Pain Med. 2017;42(3):342-350.

91. LipidRescue ${ }^{\mathrm{TM}}$ resuscitation [homepage on the Internet]. Available from: http://www.lipidrescue.org. Accessed July 08, 2018.

92. Berde CB, Strichartz GR. Local anesthetics. In: Miller RD (Ed.). Miller's Anesthesia, eighth ed. Philadelphia: Elsevier; 2015:1043.

93. Dadure C, Sola C, Dalens B, Capdevila X. Regional anesthesia in children. In: Miller RD (Ed.). Miller's Anesthesia, eighth ed. Philadelphia: Elsevier; 2015:2718.

94. American Academy of Pediatrics; American Academy of Pediatric Dentistry, Cote CJ, Wilson S; Work Group on Sedation. Guidelines for monitoring and management of pediatric patients during and after sedation for diagnostic and therapeutic procedures: an update. Pediatrics. 2006;118:2587-2602.
Local and Regional Anesthesia

\section{Publish your work in this journal}

Local and Regional Anesthesia is an international, peer-reviewed, open access journal publishing on the development, pharmacology, delivery and targeting and clinical use of local and regional anesthetics and analgesics. The journal is included in PubMed, and welcomes submitted papers covering original research, basic science, clinical studies,

\section{Dovepress}

reviews and evaluations, guidelines, expert opinion and commentary, case reports and extended reports. The manuscript management system is completely online and includes a very quick and fair peer-review system, which is all easy to use. Visit http://www.dovepress.com/ testimonials.php to read real quotes from published authors. 